[seção Contextos]

\title{
DONA JUSCELINA: CORPOREIDADE NEGRA, SABERES DO DIÁLOGO E DAS LUTAS POLÍTICAS
}

\section{DONA JUSCELINA: CORPOREIDAD NEGRA, SABERES DIALOGICOS Y DE LAS LUCHAS POLÍTICAS}

\author{
Izarete da S. de Oliveira ${ }^{1}$, Dernival Venâncio Ramos Júnior ${ }^{2}$, Olivia \\ Macedo Miranda de Medeiros ${ }^{3}$, Kênia Gonçalves Costa ${ }^{4}$, Vinicius Gomes \\ Aguiar $^{5}$, Manoel Filho Borges ${ }^{6}$. \\ ${ }^{1}$ Professora de Geografia - Secretaria Estadual de Educação/TO \\ ${ }^{2}$ Curso de História - Universidade Federal do Tocantins (UFT) \\ ${ }^{3}$ Curso de História - Universidade Federal do Tocantins (UFT) \\ ${ }^{4}$ Curso de Geografia - Universidade Federal do Tocantins (UFT) \\ ${ }^{5}$ Curso de Geografia - Universidade Federal do Tocantins (UFT) \\ ${ }^{6}$ Comunidade Quilombola Dona Juscelina. \\ Contato principal: dernivalramos@uft.edu.br
}

\begin{abstract}
Resumo: Este memorial descritivo trata da história de vida de Lucelina Gomes dos Santos, Dona Juscelina, liderança da Comunidade Quilombola Dona Juscelina. Ele foi redigido de forma colaborativa na ocasião da elaboração dos trâmites de solicitação do título de doutorado Honoris Causa junto à Universidade Federal do Tocantins. O texto descreve a trajetória de vida e destaca o protagonismo político e epistêmico de Dona Juscelina; e a articulação desses elementos com as matrizes culturais negras.
\end{abstract}

Resumen: Este memorial describe la história de vida de Lucelina Gomes dos Santos, Dona Juscelina, líder de la Comunidad Quilombola Dona Juscelina. El texto fue escrito de manera colaborativa em el momento de la elaboración del dossiê referente a la solicitación del título de Doutora Honoris Causa em la Universidad Federal de Tocantins. El texto describe la trayectoria vital y destaca su protagonismo político y epistémico, y la articulación de estos elementos con las matrices culturas negras.

A princípio, [...] todas as histórias importam. Muitas histórias importam. As histórias foram usadas para espoliar e caluniar, mas também podem ser usadas para empoderar e humanizar." (ADICHIE, 2019. p.32). Nesta 
perspectiva, este texto busca elucidar a importância da matriarca Lucelina Gomes dos Santos, Dona Juscelina, uma das maiores expoentes da identidade negra na comunidade quilombola Dona Juscelina e em todo o norte do Estado do Tocantins. O nome da comunidade é um reconhecimento de seu protagonismo político interno e externo à comunidade.

Esta comunidade quilombola está localizada no Município de Muricilândia, no Estado do Tocantins, região norte do Brasil, com acesso pela rodovia TO-222 no sentido leste a oeste no portal da Amazônia Legal.

Dona Juscelina, nascida em 24/10/1930, na cidade de Nova lorque no Maranhão, é neta de uma cativa. Benzedeira, devota e romeira de Padre Cícero, do Divino Espírito Santo, também é lavradora, parteira, quebradeira de coco e griô, presidindo o Conselho de Griots da Comunidade desde a fundação. Ser griô é ter a missão de repassar os saberes e história para os mais jovens, e assim, propiciar também os conhecimentos dos ancestrais, além de ensinar como é a organização da comunidade e sua historicidade.

Assim, as memórias estão sob os cuidados dos griôs desta comunidade, principalmente da matriarca, pela importância que possuem, são passadas à juventude quilombola, como forma de resguardar os costumes e as próprias referências. Estas, as memórias, são fortalecidas por onde a matriarca ecoa sua ancestralidade: nas escolas, universidades, nos trabalhos acadêmicos, nas ruas quando manifesta as comemorações, nos cortejos, nas praças públicas e nas redes sociais (nos territórios virtuais).

Dentre as potentes experiências da matriarca, enquanto parteira exerceu por 25 anos a missão de ajudar novas vidas a virem ao mundo. Por entre suas mãos a vida fluiu como o rio, era por este mesmo caminho que recebia a cada nova vida, o título de mãe de pegação ou Mãe Celina. As mesmas mãos que benzem e abençoam ao pedido "bênção Mãe Celina!" são as mãos, desta senhora anciã líder e serva de Deus, as quais se erguem com Fé e se sustentam nos benditos, que são orações e cantos a serem puxados e ecoados nas penitências e romarias.

Quantas vidas frágeis e pequenas cresceram e estão por aí pelo mundo afora. A matriarca sabe quantos filhos foram semeados na comunidade e em tantos outros lugares. O sentimento de mãe/vó, de mulher que ama os seus, de 
liderança que luta pelos seus the é inerente. Contudo, e os seus? Nutrem o mesmo sentimento por esta mulher provedora de vida, identidade e cultura?

Conforme as narrativas da matriarca, enquanto parteira, realizou 583 partos no decorrer de sua profissão. Partos eram realizados na comunidade e em regiões vizinhas, sendo uma profissão que exigiu e exige conhecimentos da anatomia humana. Dona Juscelina praticou esse ofício apesar de não ter tido o ensino formal para tal. Esta aprendera com suas ancestrais os segredos de realizar um parto, imbuindo sua missão de mística e ritual para garantir as vidas que desta dependiam: mãe e filho.

Atualmente, aos(90) anos, esta não é aposentada e vive de uma pensão, direito adquirido por ser viúva do primeiro casamento. Também é viúva do $2^{\circ}$ casamento, este último lhe faz brotar a saudade quando fala do falecido marido que foi seu companheiro de muitas lutas. Este compartilhava o espírito de luta e apoiava a participação da matriarca, Dona Juscelina, na política do lugar onde viviam. . Com família composta por netas, netos, bisnetas e bisnetos, a matriarca atualmente vive numa residência própria, que também é sede da Associação Quilombola Dona Juscelina.

Ela também é portadora do Título de Cidadã Muricilandense, título concedido pela Câmara Municipal de Muricilândia no ano de 2012 pelos relevantes serviços prestados à Cidade de Muricilândia na construção de uma comunidade negra quilombola, resgatando e incentivando a cultura e os direitos desta comunidade.

No ano de 2016, como reconhecimento por sua importância na luta em defesa dos direitos da comunidade quilombola, recebeu o Prêmio Boas Práticas em Direitos Humanos - Categoria VIII - Igualdade Racial, realizado pela Secretaria de Cidadania e Justiça - Seciju do Estado do Tocantins.

O reconhecimento do trabalho e da importância para a construção histórico-social do estado do Tocantins é, certamente a ideia que centraliza o esforço justo e meritório para atribuir o título de Doutora a Dona Juscelina. . Doutora por direito e por mérito devido ao acervo cultural do qual é portadora e à grandeza de sua representatividade na construção da Comunidade Quilombola Dona Juscelina! Direito conquistado, parafraseando o canto principal que é entoado no término do teatro da abolição na Festa do 13 de 
Maio, "agora negra pode ser doutora, deputada e Senadora! Não tem mais preconceito de cor!!".

Dentre as oportunidades de ouvir as narrativas da matriarca, há momentos interrompidos por choro e soluços e não há nada a se fazer além de apenas absorver, ouvir, aprender e imaginar os sofrimentos que esta mulher na trajetória de sua vida já sentiu e viveu. Sua epiderme tem muitas histórias impregnadas a serem narradas, ouvidas e sentidas. É preciso deixar a dor fluir as memórias doloridas e assim compreender o sentido das lutas desta comunidade, desta mulher negra!

Neste contexto, a matriarca Dona Juscelina é definida com precisão por Ratts (2020)"[...] uma biblioteca aberta...estando ela preparada para me receber, necessitei ver, ouvir e, também, silenciar diante dessa pessoa-lugar, pessoa-saber/fazeres/poderes, a exemplo das/os griôs e das lideranças. E continua, [...] a pessoa-biblioteca Juscelina Gomes ..." uma liderança que orientou e orienta seu povo, sua comunidade rumo a libertação ao assentarem no território ancestral de direito.

São nas narrativas que a matriarca externa com orgulho que sua raiz era cativa, ou seja, a avó fora negra escravizada e ser negra é motivo de orgulho e valor. Ela aponta a época de sua chegada nesta comunidade, em 1962, junto com seu pai, mãe, irmãos, sobrinhos, filhas, cunhados e outros parentes após sua diáspora do Maranhão até o Tocantins em busca de um local melhor para viver. Essa busca por uma vida melhor é ainda um reflexo da assinatura da Lei Áurea, pois tal lei libertou os negros escravizados, mas não Ihes deu condições para que pudessem se inserir no corpo social.

Com a matriarca veio também um dos seus maiores legados: uma festa comemorada desde sua infância. Dona Juscelina recebeu a missão de dar continuidade a esta manifestação cultural enquanto viva fosse. A tradição da festa "O 13 de Maio" foi repassada pelo tio Claro Preto do Saco quando a matriarca tinha vinte anos de idade. Na festa, a princesa Izabel é tida como redentora pela matriarca e seus ancestrais, pois foi por meio da assinatura desta princesa que o povo negro escravizado teve a tão desejada libertação.

Sempre que a matriarca narra a respeito da principal festa da comunidade, fala com sentimentos que afloram em suas memórias. Assim temos a narrativa desta griô, que narra como foi e como era a realidade na 
comunidade quando a matriarca deu início aos primeiros anos de comemorações desta festa,

[...] tinha que falar umas palavras e ela discursava também, explicando pro povo como é que era, como é que num era, o que significava a Princesa Izabel, os escravos, os meus senhores, o que que [...] eu cunheci escravos, tudo! Então aquilo ali me fortificou! Aí foi o tempo que escrevi um pouquinho pra ela, pra mostrar pro povo! Que tem gente aqui que ainda está dormindo! (Griô Dona Cícera, entrevista cedida em 31 de agosto de 2017

É neste dia que a matriarca ecoa cantos e dança com os quilombolas desta comunidade, uma forma de internalizar o que é ser quilombola e de compreender o que é ser povo negro na sociedade brasileira, sem esquecer como esta sociedade é estruturada.

Atualmente a estrutura organizacional da comunidade tem a matriarca como o maior expoente de ancestralidade. Sem ela, sem suas práticas e manifestações e sem a sua resistência, seria impossível reconhecer a comunidade como comunidade de remanescente quilombola. É a partir de sua atuação política que, com muita sabedoria e habilidade, ela articula os espaços políticos em prol das demandas da comunidade.

Nesta luta engajada por Dona Juscelina e outras lideranças, criou-se o Coletivo de Griôs, os responsáveis pelas memórias locais, onde a matriarca é a Presidente de Honra, compondo o coletivo de sete anciãos com conhecimentos que não devem ser esquecidos e são repassados aos aprendizes de griôs.

\section{Dona Juscelina: corpo em movimento nos saberes de lutas e conquistas}

A historicidade da formação desta comunidade decorre do processo de autodefinição iniciada no ano de 2006, com a vinda do Prof. Luiz Carlos Benedito a esta comunidade negra na busca de manifestações de cultura negra que fossem resquícios de remanescente da escravidão.

Este foi apresentado então a Dona Juscelina. Negra, matriarca de uma família numerosa, com ancestralidade de ex-cativa, ela chamou a atenção dele por realizar a festividade em alusão ao 13 de Maio, Dia da Abolição da Escravatura, já que em pesquisa, nenhuma outra comunidadeno Brasil comemora esta data tão emblemática. No então ano de 2008, inicia-se a 
organização da documentação para a certificação e, em 2009, a comunidade é certificada como remanescente de quilombo.

Ressalta-se que a identidade se consolida quando o quilombola se autodefine como quilombola e este autoreconhecimento contribuiu para a certificação de autodefinição. Conforme consta nos registros oficiais da comunidade quilombola, em 25 de março de 2010, às vinte horas, realizou-se uma Assembleia Geral na casa da matriarca Dona Juscelina Gomes dos Santos para a criação da Associação Quilombola Dona Juscelina enquanto entidade jurídica.

A matriarca, nestas reuniões, sempre enfatiza o valor que todos os afrodescendentes carregam para a existência da comunidade, da cultura e para a garantia dos direitos que foram conquistados, cumprindo os deveres dela de líder e reconhecendo que a luta é desigual com o grande capital.

$\mathrm{Na}$ região onde a comunidade está localizada, a expansão do agronegócio coloca em risco o direito dos povos quilombolas à terra, acirrando o número de conflitos, principalmente da Amazônia Legal. Isso reflete nos casos de escravidão por dívida, demandando a atuação política da matriarca Dona Juscelina no combate a este problema social presente na comunidade. Ela não age sozinha, tendo parceria com a Comissão Pastoral da Terra, representada por Frei Xavier. A comunidade não possui território efetivado, o que torna a luta quilombola mais árdua e exige uma tomada de consciência pelos quilombolas na efetivação deste direito: direito à terra.

É uma comunidade possuidora de uma compreensão de mundo que se forma através das narrativas e das oralidades ancestrais que comandam a organização de mundo que a rodeia. Sua guia, a matriarca, desde os primórdios, tem enfrentado tanto grandes fazendeiros e as lutas pela terra que os acompanham, quanto a morosidade do Estado.

A casa da matriarca é a sede da Associação da Comunidade Quilombola Dona Juscelina, local onde ocorrem as reuniões, os eventos sociais, religiosos, culturais e políticos. Assim, para os momentos religiosos, a matriarca mantém o altar sempre organizado e disposto para a sua prática religiosa. Onde a matriarca reside é o centro literal e figurativo desta comunidade quilombola. As práticas religiosas realizadas por Dona Juscelina, como as penitências, romarias e comemorações de santos com rezas e confraternizações, mantêm a 
união entres os quilombolas e os não quilombolas. De fato, essas práticas religiosas são um dos caminhos construídos por dona Juscelina para agregar e criar laços fraternos entre comunidade interna e externa do quilombo, evidenciando com distinta clareza o protagonismo estratégico de Dona Juscelina na promoção da cultura de paz entre culturas, povos e comunidades tocantinenses.

Uma das maiores preocupações da matriarca é com a educação, desde o nível básico ao superior. O desenrolar das metodologias de ensino, o acesso à bolsa quilombola permanente e ao transporte escolar - para que os estudantes se desloquem até aos centros universitários em Araguaína - tudo isso é assunto relevante para a líder. É recorrente a matriarca receber grupos de estudantes tanto do ensino básico quanto do superior que querem ouvi-la e saber suas histórias, que precisam ser contadas, ouvidas e sentidas.

Há um tronco ou pelourinho instalado na frente da casa da matriarca, um símbolo emblemático com forte presença da história dos castigos que o povo negro escravizado sofreu e um marco que rememora a presença de povo remanescente de quilombola na Comunidade Quilombola Dona Juscelina. É uma exposição permanente e tem o objetivo de lembrar o fundamento da principal festa que é realizada pela matriarca, sua família e todos os quilombolas desta comunidade. Talhada no tronco está a data da chegada da matriarca nesta comunidade com toda sua cultura de matriz africana. É um espaço que proporciona uma reflexão sobre a formação do povo brasileiro e do próprio povo quilombola desta comunidade e suas representatividades.

Todo este panorama é discutido nos espaços escolares, um lugar de interlocução entre a matriarca e a comunidade, a exemplo do Colégio Estadual Marechal Costa e Silva, onde é realizado o Fórum da Consciência Negra. Este fórum, juntamente com o Projeto Negritude, trata de temas étnico-raciais e abre espaços para participação de público externo, majoritariamente acadêmico, e de jovens locais para construir uma postura política fortalecida por meio deste fórum.

É neste fórum que acontece a realização do "Projeto Qual a Minha Cor?", desenvolvido pela Escola Estadual de Muricilândia, que é um momento que permite reflexão sobre a importância do combate ao racismo, à 
discriminação e ao preconceito, valorizando os conhecimentos locais e agregando a juventude nessa luta pela conquista do território ancestral.

Desta maneira, a principal manifestação cultural deste povo quilombola possui três momentos bem definidos, organizados conforme determina a matriarca. Primeiro ocorre a Alvorada, que acontece às 04 horas da madrugada. Depois ocorre a organização do espaço do teatro a céu aberto. $E$ então vem o ápice do dia: a realização do Teatro da Abolição, onde é retratado o momento em que a princesa Izabel assina a Lei Áurea e declara o fim da escravidão do povo negro.

O engajamento de Dona Juscelina e de lideranças quilombolas no meio político local Ihes permite transitar nos espaços de poder que são em grande parte ocupados por representatividade eurocêntrica. A exemplificar, na Câmara Municipal de Muricilândia, foi criada a Lei n 255 de 15 de abril de 2004 que declara feriado municipal no dia 13 de maio, em homenagem ao "Dia da Folia Negra". Essa lei garante a realização das apresentações e encenações nas diversas ruas da cidade enquanto acontecer a manifestação cultural.

A singularidade desta manifestação foi fundamental para que a comunidade fosse reconhecida como remanescente de quilombo. Marcando o início do processo de reconhecimento, ocorreram três reuniões em datas e locais diferentes na comunidade. A primeira reunião ocorreu na casa da matriarca e o local foi reconhecido como a sede do quilombo por não haver uma sede própria.

Nos primórdios, para a certificação da comunidade como remanescente quilombola, foi preciso a voz potente da matriarca para a divulgação do conclame para que todos se unissem e lutassem principalmente pelo direito a terra. E, para que isto pudesse acontecer, todos e todas que se autorreconhecessem como quilombola deveriam preencher um cadastro. No início do cadastramento, houve resistência deste povo negro, e foi necessário ocorrer várias reuniões em que a matriarca explicava o que era ser quilombola e por que eles eram quilombolas, rememorando as práticas sociais que fazem parte do cotidiano.

Nos arquivos historiográficos da comunidade, do ano de 2008 até dezembro de 2016, conforme os registros no Livro Ata, ocorreram vinte 
reuniões em espaços sociais diversos: a casa da Matriarca Dona Juscelina, a Praça da Igreja Católica, o salão paroquial e o salão do Balneário Água Viva.

Esses eram espaços de discussões sobre assuntos inerentes às questões dos quilombolas, que eram debatidas e informadas de forma democrática com a participação de todos os quilombolas associados. Nestes registros, é possível obter a época em que foi informado aos quilombolas sobre a entrada na documentação do quilombo na Secretaria Estadual de Cidadania e Justiça em Palmas e na Fundação Palmares em Brasília, para recebimento da Certidão de Autodefinição como Comunidade Remanescente de Quilombola.

Após quatro anos do início da busca de direitos quilombolas, em 25 do mês de março do ano de 2010, houve uma Assembleia Geral na casa da matriarca para a criação da Associação Quilombola Dona Juscelina, tendo como objetivo no capítulo um (01), da Denominação, sede e fins, como preconize o Art. $1^{\circ}$ :

[...] A Associação da Comunidade Quilombola Dona Juscelina, também designada pela sigla, ACQDJ, fundada aos vinte e cinco dias do mês de março do ano de dois mil e oito (25/03/2008). É uma Associação, sem fins econômicos, que terá duração por tempo indeterminado, de caráter cultural e social, de gestão comunitária, composta por número ilimitado de associados, com sede em Muricilândia, na Avenida Antônio Carneiro Dourado, s/n, centro e foro na cidade de Araguaína-TO [...] (Estatuto da ASQDJ. MuricilândiaTO, 13/04/2013).

Assim, por meio de votação foi criada a primeira associação, constando na presidência, Juscelina Gomes dos Santos e os seguintes conselhos: Fiscal, Cultural, Comunitário, Departamento de Radiodifusão Comunitário. As funções deverão ser exercidas no biênio 2010-2011. Isso foi um marco importante na organização jurídica da comunidade.

A partir destas conquistas políticas e jurídicas, a comunidade começou a ter acesso a políticas públicas ao receber cestas básicas. Como no início foi em número insuficiente para as famílias cadastradas, exigiu-se da diretoria a contemplação de todos, atendendo às demandas.

Há participação de representantes da comunidade em ações políticas também fora da comunidade, como foi na I MARCHA NACIONAL QUILOMBOLA, ocorrida em Brasília no dia 7 de novembro com o lançamento da campanha: "Em defesa dos direitos quilombolas". A matriarca Dona Juscelina Gomes dos Santos, a vice-presidente Francisca Gomes dos Santos e 
outras lideranças participaram. Nessa ocasião, foi derrubada a ação defendida pela então Senadora Kátia Abreu contra o direito ao chão da terra dos quilombolas, de onde tiram o sustento da vida.

Outra ação política importante na luta é a criação do site do quilombo, um espaço de informação, cultura quilombola, divulgação e resistência acessível a todos os quilombolas. Nestes espaços, por exemplo, são publicadas as informações para que os quilombolas desta comunidade saibam e tenham acesso aos seus benefícios de direito.

A matriarca também participou da Feira de Talentos ocorrida em Palmas, em que houve a apresentação de danças tradicionais da comunidade, como o Rebolado, uma ressignificação da Festa do 13 de Maio.

A parceira com o Centro de Referência e Assistência Social - CRAS oportunizou a realização de atividades desenvolvidas especificamente para atendimento das pessoas idosas, com inclusão social, atividades de lazer e atividade laboral, gerando uma melhor qualidade de vida. Neste espaço, valoriza-se a importância dos griôs, os quais fazem parte do público atendido pelo órgão.

Em toda e qualquer atividade que envolve a comunidade quilombola, consulta-se a matriarca como uma forma de respeitar e reconhecer sua liderança enquanto matriarca e por sua representatividade. Mesmo documentos que são elaborados e protocolados junto aos representantes das esferas de governo devem receber o aval de Dona Juscelina. Desde a elaboração e apresentação de uma carta da comunidade quilombola ao governador do Estado solicitando a contemplação da construção da sede para a comunidade, mantém-se a necessidade, na realização de reuniões e eventos, de um ponto de referência oficial para as ações dos quilombolas, já que ainda é uma demanda da comunidade ter uma sede própria.

A Comunidade Quilombola Dona Juscelina vem formando uma organização que permite a participação dos quilombolas ao deliberar-lhes responsabilidades para que todos cuidem da comunidade, assim a contemplação de benefícios será de forma igualitária e com equidade. Dessa forma, lideranças se destacam em nichos específicos que vão desde contar e rememorar as histórias ancestrais até organizar reuniões, fazer agendamentos e cumprir parte burocrática. 
Durante a realização de rodas de conversas para avaliar a situação da comunidade pela diretoria quilombola, são pontuadas situações de retrocessos dentre estas, como a estagnação nas ações ocasionadas pelo atraso no acesso aos benefícios, a exemplo das cestas básicas. Também houve a necessidade de atualizar a documentação e o Estatuto e realizar novas eleições para uma nova diretoria, entre outras demandas urgentes.

Assim, em abril de 2013, realizou-se a segunda eleição para diretoria da associação quilombola, estruturada da seguinte forma: Conselho Fiscal, Conselho Cultural e Conselho Comunitário de Radiodifusão. Os membros da nova diretoria foram empossados para o exercício do biênio 2013-2014 e a presidente da associação eleita é sobrinha da matriarca, algo que contribuiu para agregar valor à luta quilombola.

As lutas do quilombo Dona Juscelina estão inscritas na organização que os quilombolas vêm engajando para a abertura do processo de regularização do território ancestral desde 2006, quando houve a primeira visita de um representante legal, o Coordenador dos Afrodescendentes Quilombolas do Estado do Tocantins, Luiz Carlos Benedito. Este fez enfrentamento para garantia de direitos dos povos quilombolas em nosso Estado.

Em dezembro de 2016, ocorreu pela terceira vez uma eleição para formar nova diretoria e foi eleita a chapa única para exercício 2017-2018. Para assumir a presidência da associação, Lucilene Gomes do Nascimento, neta da matriarca, foi uma escolha que firmou ainda mais as raízes da ancestralidade nesta comunidade quilombola, além de fortalecer a representatividade da força da mulher quilombola numa luta que é cotidiana.

Somente quilombolas fizeram parte desta nova diretoria e compuseram os seguintes conselhos: Fiscal, Cultural e Comunitário de Radiofusão. Com grande destaque, formou-se o Conselho de Griôs, do qual a matriarca é a presidente. Assim, constituído por três anciãs e cinco anciãos, os quais são detentores das memórias deste povo quilombola.

Para fazer o cadastramento, de forma geral, primou-se pela descendência direta dos fundadores, o vínculo ancestral. Se em uma dada casa houver os dois vínculos ancestrais, o cadastro é feito em nome da mulher, como uma forma de empoderar e valorizar a participação feminina. 
Portanto, há aí algo muito importante: a valorização não só da mulher, como também de uma mulher negra.

Vencer cada etapa que surgia no processo de formação da comunidade quilombola Dona Juscelina foi uma luta árdua que começou com o importante passo de esclarecer para o quilombola o que é ser um quilombola a fim de promover a consciência da sua identidade. Compreender os passos jurídicos e até mesmo políticos exige um conhecimento direcionado pelo espírito de luta e a capacidade de comunicação eficaz.

Hoje, o sentimento de pertencimento, que é parte de como se sentem enquanto quilombolas, é evidente, especialmente quando eles afirmam que são felizes por serem respeitados e terem liberdade após tantas lutas políticas e étnico-raciais que ocorreram durante a certificação e em busca da titulação do território ancestral.

A identidade negra quilombola é expressa veementemente no festejo da abolição, que ocorre durante três dias numa alusão à comemoração de quando o tio da matriarca recebeu a notícia da assinatura da Lei Áurea pelo telégrafo, como narra a matriarca;

[...] quando foi declarado o telegrama, é o cumeço. Então ele foi, aí chegou um homem. Claro Preto! - Hã! - Lá na estação tem um telegrama pra você! Foi lá. Então a Princesa Izabel era filha do Dom Pedro II. Aí o certo, que ela vai e fala: Claro Preto... o telegrama: Claro Preto apesar que tô Ihe dando a primeira notícia da felicidade! Eu já reuni com meus oito cumpanheiros, meu pai saiu pra guerra e nós vamos trabaiar pra acabar com a escravidão no Brasil. E Claro ficou muito alegre, naquele tempo não havia fuguete, não havia nada. Era umas ronqueiras, de ferro, eu mermo ainda vi [...](Matriarca Dona Juscelina, entrevista cedida em 02 de dezembro de 2016)

Por um fio, ou seja, pelo telegrama, a família da matriarca fica sabendo da assinatura da lei. E as comemorações de três dias por esta conquista são realizadas atualmente da mesma forma que ocorreram no passado.

Com a reorganização dos espaços de interlocução entre os anciãos e a juventude acadêmica, o diálogo entre gerações ocorre por meio do seminário com mesas de debates organizado pelos acadêmicos contemplados com a bolsa quilombola. Isso mostra a importância das cotas como uma política pública que beneficia a comunidade. Levando-se em conta os conhecimentos que possuem, observamos as ponderações das relações sociais, do modo de 
agir da juventude num sentido que vai desde a busca de direitos até a questão da preservação dos saberes tradicionais. Quanto à preservação dos saberes tradicionais, estes são transmitidos no cotidiano da comunidade por meio da oralidade, da música, da escrita, das romarias, da arte como um todo, do artesanato com palha de coco babaçu e do conhecimento do percurso do rio Muricizal.

O Conselho de Griôs é um instrumento contemplado no estatuto da associação a partir de uma alteração necessária. Surge em razão de ser percebida a dificuldade que o negro da comunidade tem de se aceitar na condição de quilombola. Isto gera uma preocupação nas lideranças, especialmente da Matriarca Dona Juscelina: se o adulto não se aceita como negro, quando os mais velhos morrerem, como ficarão os jovens? Quem irá carregar a tradição, fazer com que as manifestações não se extinguam?

Vale ressaltar que os cortejos realizados nos espaços públicos, que são manifestações lideradas pelas mulheres quilombolas, percorrem as principais ruas da cidade anunciando como será vivido o dia dedicado às memórias da alegria da libertação da escravidão. Como a própria matriarca assevera: "[...] é 13 de Maio! É o sufrimento, eu festejo é o sufrimento dos negros! Eu sou uma neta de uma cativa, num conheci, graças a Deus! Mas, minha vó era cativa! Foi cativa! [...]" (Matriarca Dona Juscelina, entrevista cedida em 03 de dezembro de 2016).

Nesta narrativa a matriarca frisa não ter sido cativa, pois foi criada pelo padrinho, rico e político. Ele ensinara-lhe a etiqueta e a maneira de receber o cidadão e cidadã, de como chegar e sair em qualquer lugar no meio da sociedade. Isso nos faz lembrar a trajetória de mulheres negras, como Lélia Gonzales que [...] transitou entre circuitos negros e brancos sem perder de vista seu horizonte racial [...] (RATTS, 2010. p. 156). Assim, a matriarca, que aprendeu a circular entre a casa grande e a senzala no seu passado, hoje, circula entre as memórias do passado e as lutas políticas em prol da estrutura organizacional desta comunidade.

Sob a liderança de uma mulher negra e anciã, a comunidade vem acessando políticas públicas, dentre estas o acesso à bolsa quilombola em espaços universitários, atendendo aproximadamente cinquenta acadêmicos contemplados em diferentes universidades na cidade de Araguaína. Estes 
acadêmicos participam de rodas de conversas com Dona Juscelina, momentos em que esta reforça a importância do direito à educação e do combate ao epistemicídio. Quanto à participação da juventude, existem dois instrumentos de luta: o Núcleo de Estudos Afro Quilombola - NEAQ e o Coletivo de Juventude, o qual vem sendo articulado e organizado por jovens mulheres quilombolas.

Com todo o engajamento da matriarca Dona Juscelina, conquistas foram alcançadas, como: a certificação de autodefinição; a constituição de uma associação quilombola consistente, pautada na democracia e com a participação dos quilombolas; e a criação de importantes instrumentos de ação política, como o Conselho de Griôs, o Núcleo de Estudos Afro Quilombolas NEAQ, o Coletivo da Juventude, e tantas outras representações políticas.

Deste modo, o ativismo de Dona Juscelina traz à luz seu empoderamento, que inspira outras mulheres negras. Como assevera Davis (2017), [...] se quisermos elevar a condição de toda a nossa comunidade à medida que escalamos as alturas do empoderamento, devemos estar dispostas a oferecer uma resistência organizada contra as crescentes manifestações de violência racista por todo o país [...] (DAVIS, 2017.p.20). Manifestações racistas estas que também são combatidas em enfrentamentos nesta comunidade.

Neste panorama e com uma visão que contempla as várias interfaces desta comunidade quilombola, tem-se a matriarca como expoente da ancestralidade negra. Em interlocuções entre anciãos e jovens, é ponto de discussão a apropriação cultural, como adverte Ribeiro (2019) [...] a discussão pertinente é aquela que denuncia o quanto culturas negras e indígenas foram expropriadas e apropriadas historicamente [...] (RIBEIRO, 2019.p. 70). Neste contexto, mantido o processo pelo qual as memórias são semeadas, garantese o legado dos saberes local.

A manutenção do principal rito da comunidade e de suas tradições - a Alvorada, a pintura da pele e o teatro a céu aberto -, que são carregadas de simbolismos e significados, é resultado desse processo de semeadura de conhecimento. Desta maneira, [...] por isso também busco a primeira narração, a que veio antes da escrita. Busco a voz, a fala de quem conta, para se misturar a minha. (EVARISTO, 2018. p.11). E ficaram em nossas memórias as narrativas e histórias vividas nesta comunidade, especialmente em convivência 
com Dona Juscelina, uma mulher enérgica, que articula ideias e culturas, firme nas suas decisões, acolhedora e muito sábia.

A luta pelo território na Comunidade Quilombola Dona Juscelina é contínua desde 2006, ano em que se deu início ao processo de formação socioterritorial. É uma das 45 comunidades certificadas e uma das 09 localizadas na região Norte do estado. A própria estrutura organizacional da comunidade demonstra que são muito intensas as lutas diárias pelo território ancestral, ainda não mão de fazendeiros da região.

Certamente, [...] a história da África registra muitas rainhas guerreiras [...] (SEMOG, 2006. p. 200), contudo a comunidade quilombola Dona Juscelina tem sua rainha e guerreira, a matriarca Dona Juscelina que a cada dia luta [...] para vencer as barreiras impostas ao mesmo tempo pelo racismo e pelo machismo [...](SEMOG, 2006.p. 200), preconceitos que são obstáculos frequentes não só nas lutas pelas quais passam as comunidades remanescentes de quilombo, mas também nas batalhas que mulheres negras enfrentam por todo o Brasil.

Assim, foi essencial a chegada da matriarca e de toda a sua família a esta comunidade após migrarem do Maranhão em busca de um lugar que lhes permitisse condições de viver, carregando no bojo a cultura de matriz africana. Tal cultura é vivamente representada pela comemoração do dia 13 de maio, a festa da Abolição, um instrumento cultural de luta e que fortalece o ativismo político da matriarca.

Enquanto corpo que carrega saberes políticos direciona as lutas de sua comunidade e de outras que buscam seus conhecimentos para serem guiados no melhor caminho com muita sabedoria. Ressalta-se quando houve a ocupação da Universidade Publica Federal-UFT em Araguaína, liderados por acadêmicos quilombolas e indígenas em junho de 2018.

Um ato de repúdio contra a proposta do governo federal de cortar a bolsa auxílio-permanência, organizado por acadêmicos (as) quilombolas das comunidades: Pé do Morro (Aragominas), Dona Juscelina (Muricilândia) e Cocalinho (Santa Fé), além de lideranças indígenas da aldeia Xambioá (Santa Fé), resultando na instituição do Movimento Estudantil Indígena e QuilombolaMEIQ.

Assim, para fortalecer o movimento de ocupação da universidade, a matriarca Dona Juscelina se fez presente e narrou sobre as dificuldades que 
há para os jovens quilombolas estarem na universidade e em tantos outros lugares de poder, reconhecendo que o movimento é legitimo por direito.

É esta corporeidade negra feminina que se movimenta e movimenta outras corporeidades negras, constituindo identidade de outras e da própria comunidade quilombola. No mesmo sentido, essa corporeidade negra de Dona Juscelina forma e (com)forma uma malha de saberes que, permanentemente partilhados, fomentam debates e diálogos sobre aspectos importantes das demandas de inserção social da Universidade Federal do Tocantins. A valorização das diversas formas identitárias que compõe o estado do Tocantins, demandada no PDI da Universidade Federal do Tocantins, articula e fortalece o propósito de atribuir o título de Doutora Honoris Causa à Dona Juscelina em função de esta, desde sua chegada ao estado, atuar permanentemente pelo diálogo, pelo entendimento e na construção de uma cultura de paz entre os diversos grupos sociais, políticos e étnicos de nossa região.

A atuação de Dona Juscelina, em constante trânsito entre os saberes tradicionais e os acadêmicos, fomenta e fortalece a imagem da Universidade Federal do Tocantins como uma das mais importantes precursoras do desenvolvimento humano do nosso Estado, e justifica os esforços envidados em reconhecer sua representatividade política e social para as comunidades e para o norte do Estado, ao atribuir-Ihe o título de Doutora.

\section{Bibliografia}

ADICHIE, Chimamanda Ngozi. O perigo de uma história única. $1^{\text {a }} \mathrm{Ed}$. São Paulo: Companhia das Letras, 2019.

DAVIS, Angela. Mulheres, cultura e política. $1^{\text {a }}$ ed. São Paulo: Boitempo, 2017. EVARISTO, Conceição. Becos da Memória. $4^{\text {a }}$ ed. Rio de Janeiro: Pallas, 2018.

RIBEIRO, Djamila. Pequeno Manual Antirracista. $3^{a}$ ed. São Paulo: Companhia das Letras, 2019.

RATTS, Alex. Lélia Gonzalez. São Paulo: Selo Negro, 2010.

RATTS, Alex. Uma geo-grafia de estudos e pesquisas com as diferenças étnicas, raciais e territoriais. In: FREIRE, Adriana Feitosa et al (Orgs.) Cultura e 
Território em foco, uma abordagem interdisciplinar. Editora Fi. Porto Alegre. 2020. Disponível em: http://www.editorafi.org.

SEMOG, Éle. Abdias Nascimento: o griot e as muralhas. Rio de Janeiro: Pallas, 2006.

OLIVEIRA, Izarete da Silva de. Território e territorialidade nos limites do rural e urbano na Comunidade Quilombola Dona Juscelina em Muricilândia-TO. Dissertação de Mestrado Acadêmico. Universidade Federal do Tocsntins. Araguaína-TO. Curso de Pós-Graduação Estudos em Cultura e Território, 2018. 